\title{
Novel therapeutic strategy targeting the Hedgehog signalling and mTOR pathways in biliary tract cancer
}

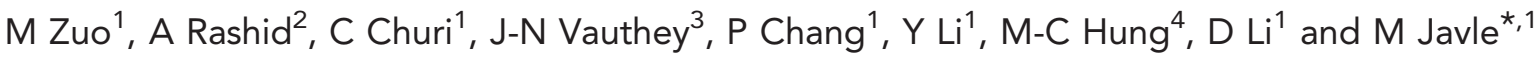 \\ ${ }^{1}$ Department of Gastrointestinal Medical Oncology, The University of Texas MD Anderson Cancer Center, Houston, TX, USA; \\ ${ }^{2}$ Department of Pathology, The University of Texas MD Anderson Cancer Center, Houston, TX, USA; ${ }^{3}$ Department of Surgery, \\ The University of Texas MD Anderson Cancer Center, Houston, TX, USA and ${ }^{4}$ Department of Molecular and Cellular Oncology, \\ The University of Texas MD Anderson Cancer Center, Houston, TX, USA
}

Background: Activation of the PI3K/mTOR and Hedgehog (Hh) signalling pathways occurs frequently in biliary tract cancer (BTC). Crosstalk between these pathways occurs in other gastrointestinal cancers. The respective signalling inhibitors rapamycin and vismodegib may inhibit BTC synergistically and suppress cancer stem cells (CSCs).

Methods: Gene expression profiling for p70S6k and Gli1 was performed with BTC cell lines. Tumour and pathway inhibitory effects of rapamycin and vismodegib were investigated in BTC preclinical models and CSCs.

Results: Rapamycin and vismodegib synergistically reduced BTC cell viability and proliferation. This drug combination arrested BTC Mz-ChA-1 cells in the G1 phase but had no significant effect on the cell cycle of BTC Sk-ChA-1 cells. Combined treatment inhibited the proliferation of CSCs and ALDH-positive cells. Nanog and Oct-4 expression in CSCs was decreased by the combination treatment. Western blotting results showed the p-p70S6K, p-Gli1, p-mTOR, and p-AKT protein expression were inhibited by the combination treatment in BTC cells. In an Mz-ChA-1 xenograft model, combination treatment resulted in 80\% inhibition of tumour growth and prolonged tumour doubling time. In 4 of 10 human BTC specimens, tumour p-p70S6K and Gli1 protein expression levels were decreased with the combination treatment.

Conclusions: Targeted inhibition of the PI3K/mTOR and Hhpathways indicates a new avenue for BTC treatment with combination therapy.

Biliary tract cancers (BTCs), which include cancer of the biliary duct, cholangiocarcinoma (CCA), and gallbladder cancer, are aggressive and have distinct epidemiologic patterns. A high incidence $(85 / 100000)$ of BTC has been reported for northeast Thailand, where CCA represents approximately $85 \%$ of primary liver cancers (Poomphakwaen et al, 2009). The incidence of intrahepatic CCA is rising rapidly particularly in the western world, including the United States, where an estimated 10650 people will be diagnosed with BTC in 2014, with the majority presenting at an advanced and inoperable disease stage (Siegel et al, 2014). In Latin America, particularly in Chile, and in South Asia and East Asia, gallbladder cancer is more common. Systemic treatment for BTC is commonly gemcitabine plus cisplatin, but despite treatment, the median overall survival rate is $<1$ year. Novel therapeutics based on the underlying molecular profile of these tumors will be key to changing the treatment paradigm of BTCs.

Mammalian target of rapamycin (mTOR) is a $289-\mathrm{kDa}$ serine/ threonine protein kinase of the $\mathrm{PI} 3 \mathrm{~K} / \mathrm{AKT} / \mathrm{mTOR}$ signalling pathway that regulates cell proliferation, survival, and angiogenesis. mTOR expression is common in gallbladder cancer and CCA and may have prognostic significance (Herberger et al, 2007; Leal et al, 2013; 
Moolthiya et al, 2014; Simbolo et al, 2014). Inhibition of mTOR has demonstrated anti-tumour effects in preclinical models of gallbladder cancer and CCA (Wu et al, 2007; Herberger et al, 2009; Zong et al, 2014). Furthermore, a clinical trial demonstrated a $5.1 \%$ objective response rate in BTC patients treated with the mTOR inhibitor everolimus (Buzzoni et al, 2014).

In contrast, the Hh pathway plays a fundamental role in stem cell maintenance, cell differentiation, tissue polarity, and cell proliferation. Dysregulation of the Hh signalling pathway has been associated with the presence of cancer stem cells (CSCs) and implicated in the initiation of pancreatic and other cancers (Rodova et al, 2012). Constitutive activation of the Hh pathway leading to tumourigenesis is seen in various cancers, including basal cell carcinoma and medulloblastoma. Cholangiocellular injury activates Hh ligands, which promotes dysfunctional repair and tumourigenesis. Inhibition of the Hh pathway attenuates the carcinogenesis of CCA cells and enhances necrosis. Expression analysis of human CCA samples has indicated Hh activation in almost 50\% of cases (El Khatib et al, 2013). In these cases, noncanonical Hh pathway activation appears to play a key role and can be inhibited by cyclopamine (Kim et al, 2012; Razumilava et al, 2014; Riedlinger et al, 2014).

Our group recently reported crosstalk between the mTOR/ S6K1and Hh signalling pathways in oesophageal adenocarcinoma (Wang et al, 2012). mTOR inhibition is already being investigated in the clinical setting in BTCs and modest clinical efficacy has been observed (Buzzoni et al, 2014). We hypothesised that noncanonical Hh pathway activation via mTOR plays an oncogenic role in BTC and that simultaneous inhibition of these two pathways in BTC will provide incremental clinical benefit to patients.

\section{MATERIALS AND METHODS}

Cell lines and cell culture. Human BTC Mz-ChA-1and Sk-ChA1cells were obtained from Dr. Reddy's lab (The University of Texas MD Anderson Cancer Center). Human BTC M214, M139, M156, M213, M055, M213LOH, and M213L5H cells were kindly provided by Dr. Lee's lab (The University of Texas Medical Branch). Cells were cultured in $5 \% \mathrm{CO}_{2}$ at $37^{\circ} \mathrm{C}$ in DMEM

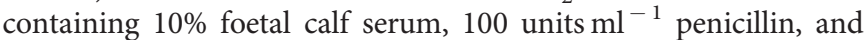
$100 \mathrm{mg} \mathrm{ml}^{-1}$ streptomycin. Cancer stem cell culture medium consisting of DMEM/F12, glutaMAX, B27 supplement, epidermal growth factor and basic fibroblast growth factor were purchased from Life Technologies (Grand Island, NY, USA).

Reagents and antibodies. Rapamycin was purchased from LC laboratories (Woburn, MA, USA) and vismodegib was obtained from Genentech (South San Francisco, CA, USA). Antibodies recognising p70S6K, Phospho-p70 S6 Kinase (Thr389), mTOR, phospho-mTOR (Ser2448), AKT, and phospho-Akt (Ser473) were obtained from Cell Signaling Technology (Danvers, MA, USA) Antibodies against Gliland phospho-Gli1(Ser84) were a kind gift of Dr. Mien-Chie Hung's lab (The University of Texas MD Anderson Cancer Center). Monoclonal anti- $\beta$-actin antibody was purchased from Sigma-Aldrich (St. Louis, MO, USA).

Cell viability assay. Biliary tract cancer $\mathrm{Mz}-\mathrm{ChA}-1$ and Sk-ChA-1 cells were seeded into white 96 -well plates at $5 \times 10^{3}$ cells per well. After incubation overnight, the cells were treated with rapamycin, vismodegib, or both at serial concentrations from 0.25 to $50 \mu \mathrm{moll}^{-1}$ for $72 \mathrm{~h}$. The CellTiter-Glo luminescent cell viability assay kit (Promega, Madison, WI, USA) was used to determine the number of viable cells in culture. Following treatment, cellular proliferation was measured according to the manufacturer's instructions. All treatments were performed in triplicate and in three independent experiments.
Colony-formation assay. Colony-formation assay was performed as described previously. In short, $1 \times 10^{3}$ viable cells were subcultured in 6-well plates in triplicate. Cells were cultured overnight and then treated with $1 \mu \mathrm{moll}^{-1}$ rapamycin, $10 \mu \mathrm{moll}^{-1}$ vismodegib, or both for $72 \mathrm{~h}$. Culture medium was aspirated, the cells were washed, and fresh complete medium was added. Cells were incubated for an additional 14 days. Thereafter, the colonies were fixed with $6.0 \%$ glutaraldehyde and stained with $0.5 \%$ crystal violet. Clonogenic cells were defined as those able to form a colony consisting of at least 50 cells.

Sphere-formation assay. To evaluate the formation of primary spheres, Mz-ChA-1 and Sk-ChA-1 cells were transferred to ultralow-adherence six-well plates (Corning, Inc., Corning, NY, USA) at a density of 5000 per well in $4 \mathrm{ml}$ of CSC medium consisting of DMEM/F12 plus glutaMAX, B27 supplement, $20 \mathrm{ng} \mathrm{ml}^{-1}$ epidermal growth factor and $20 \mathrm{ngl}^{-1}$ basic fibroblast growth factor. Tumour spheres were allowed to grow for 7 days. To establish spheres, cells were individualised by enzymatic dissociation, strained, and then plated at a density of $5 \times 10^{2}$ or $1 \times 10^{3}$ cells per well in 24-well plates ( 3 wells per treatment). Cells were treated with rapamycin $1 \mu \mathrm{mol} 1^{-1}$, vismodegib $10 \mu \mathrm{moll}^{-1}$, or both for 7 days, after which the culture medium was changed to fresh CSC medium. The resultant spheres were photographed after 14 days of culture.

Cell cycle assay. Mz-ChA-1 and Sk-ChA-1 cells were seeded in $25-\mathrm{cm}^{2}$ tissue culture flasks and then incubated with $1 \mu \mathrm{mol} 1^{-1}$ rapamycin, $10 \mu \mathrm{moll}^{-1}$ vismodegib, or both agents. After treatment for $48 \mathrm{~h}$, cells $\left(2 \times 10^{6}\right)$ were harvested by trypsinisation. Then, cells were fixed in $70 \%$ ethanol and then incubated with RNase A $\left(100 \mu \mathrm{g} \mathrm{ml}^{-1}\right)$ and propidium iodide $\left(100 \mu \mathrm{g} \mathrm{ml}^{-1}\right)$ for $30 \mathrm{~min}$. The data from 10000 cells for each sample were collected and assessed using a FACS scan (Becton Dickinson, Franklin Lakes, NJ, USA).

Quantitative reverse-transcriptase polymerase chain reaction (qRT-PCR). Total RNA was extracted from cells using the RNeasy mini kit (Qiagen, Valencia, CA, USA) according to the manufacturer's instructions. cDNA was synthesised from $1 \mu \mathrm{g}$ of total RNA using an iScript cDNA synthesis kit (Life Technologies Corp., Hercules, CA, USA). Real-time RT-PCR analysis was performed using a QuantiFast SyBR green PCR kit (Qiagen). The primer sequences were synthesised by Sigma (Supplementary Information 1). Gene expression levels were normalised against the average cycle threshold $(\mathrm{Ct})$ values for the internal control gene GAPDH. Cycle threshold values were extracted using SDS version 2.3 software (Applied Biosystems, Foster City, CA, USA). Data analysis was performed using the $\Delta \Delta \mathrm{Ct}$ method.

Flow cytometric analysis of aldehyde dehydrogenase (ALDH) activity. Mz-ChA-1 and Sk-ChA-1 cells $\left(2.5 \times 10^{5}\right)$ were treated with $1 \mu \mathrm{moll}^{-1}$ rapamycin, $10 \mu \mathrm{moll}^{-1}$ vismodegib, or both for $72 \mathrm{~h}$. The cells were then harvested via trypsinisation and stained for $30 \mathrm{~min}$ at $37^{\circ} \mathrm{C}$ using an Aldefluor kit (Stem Cell Technologies, Durham, NC, USA) following the manufacturer's instructions. Cells treated with diethylaminobenzaldehyde, a specific ALDH inhibitor, were used as a control. The ALDH-positive control population was detected using the FACS scan. ALDH-positive cells were identified with a dot plot.

Western blotting assay. Biliary tract cancer cells were treated with vehicle, $1 \mu \mathrm{moll}^{-1}$ rapamycin, $10 \mu \mathrm{moll}^{-1}$ vismodegib, or the combination of the two drugs for $48 \mathrm{~h}$. Total cellular lysates were obtained by lysing cells in a buffer containing RIPA buffer $(50 \mathrm{~mm}$ Tris- $\mathrm{HCl}, \mathrm{pH} 7.5,150 \mathrm{~mm} \mathrm{NaCl}, 1 \% \mathrm{v} / \mathrm{v}$ Nonidet P-40, 0.5\% v/v sodium deoxycholate, and $0.1 \%$ SDS) and a mixture of protease and phosphatase inhibitors. The protein concentration was measured using a bicinchoninic acid protein assay kit 
(Pierce, Rockford, IL, USA). Electrophoresis was carried out through a $4 \%-20 \%$ Ready Gel Tris-HCl precast polyacrylamide gel (Life Science Technology, Hercules, CA, USA). Gels were transferred to Hybond-C extra nitrocellulose membrane (Amersham Bioscience, Freiburg, Germany). Proteins were detected with antibodies against Gli1, p-Gli1, mTOR, p-mTOR, p70S6K, p-p70S6K, AKT, and p-AKT $\left(S^{4}{ }^{473}\right)$ Cell Signaling Technology, Danvers, MA, USA). Signals were detected by incubating the membrane with Pierce ECL western blotting substrate (Thermo Scientific, Rockford, IL, USA) and exposed to X-ray (BioExpress, Kaysville, UT, USA).

Mouse xenograft model. All experiments were performed at The University of Texas MD Anderson Cancer Center and were approved by the Institutional Animal Care and Use Committee. We examined the anti-tumour efficacy of rapamycin, vismodegib, or both in a subcutaneous cancer cell xenograft model. Nude (nu/nu) 6- 8-week-old mice were purchased from Charles River (Wilmington, MA, USA). Five million Mz-ChA-1 cells were subcutaneously injected into each flank in 50:50 PBS:Matrigel (BD Biosciences, Billerica, MA, USA). When tumours reached a mean volume of $100 \mathrm{~mm}^{3}$, animals were matched by size and distributed into four treatment groups consisting of eight mice per group. Mice were treated by oral gavage twice a day with vehicle, $1 \mathrm{mg} \mathrm{kg}^{-\mathrm{g}}$ rapamycin, $100 \mathrm{mg} \mathrm{kg}^{-1}$ vismodegib, or both rapamycin and vismodegib. Tumour volume was calculated with the formula $1 / 2\left(\mathrm{~L} \times \mathrm{W}^{2}\right)$, where $\mathrm{L}$ is length (longest dimension) and $\mathrm{W}$ is width (shortest dimension). To calculate tumour growth inhibition, the following formula was used: $\left(\mathrm{TuG}_{\text {control }}-\mathrm{TuG}_{\text {test }}\right) / \mathrm{TuG}_{\text {control }} \times$ $100 \%$, where tumour growth $(\mathrm{TuG})$ equals the final tumour size minus the pretreatment tumour size for individual treatment groups. ' $\mathrm{T}_{\mathrm{u}} \mathrm{G}_{\text {control }}$ ' refers to the growth in mice treated with vehicle only and ' $\mathrm{T}_{\mathrm{u}} \mathrm{G}_{\text {test }}$ ' refers to the growth in mice treated with rapamycin, vismodegib, or both rapamycin and vismodegib. Each mouse was killed by $\mathrm{CO}_{2}$ asphyxiation at the experimental end point or when its tumour was oversized, ulcerated, or necrotic.

Immunohistochemical analysis. Immunohistochemical was performed to examine the p-p70S6K and Gli1 protein expression levels in tumour xenografts and archival tumours from patients with resected gallbladder cancer. Xenograft tumour tissue was covered with OCT embedding compound and stored at $-80^{\circ} \mathrm{C}$ until ready for sectioning. Frozen sections were mounted on 3 -aminopropyltriethoxysilane-coated slides. For xenograft tumour tissue slides, the tissue sections were immersed in pre-cooled acetone $\left(-20{ }^{\circ} \mathrm{C}\right)$ for $10 \mathrm{~min}$ and the acetone was allowed to evaporate from the tissue sections. Human formalin-fixed, paraffin-embedded tissue sections were deparaffinised using xylene and ethanol. All sections were heated for epitope retrieval in citrate buffer ( $\mathrm{pH}$ 6.0). Endogenous peroxidase was blocked by incubation in $3 \%$ hydrogen peroxide. Sections were incubated with the primary polyclonal rabbit anti-p-p70S6K antibody at a dilution of $1: 400$, rabbit anti-Glil antibody for $30 \mathrm{~min}$ at $37^{\circ} \mathrm{C}$, and then biotin-conjugated secondary goat anti-rabbit antibody (Vector Laboratories, Burlingame, CA, USA) for $30 \mathrm{~min}$. Sections were stained with the avidin-biotin complex technique using reagents as described by the manufacturer (Vectastain kit, Vector Laboratories). Positive labelling was visualised by incubating the slides with horseradish peroxidase-conjugated streptavidin (DAB substrate kit, Vector Laboratories). Sections were counterstained with haematoxylin. Stained slides were dehydrated by sequential steps through a graded series of alcohol washes and xylene (Fisher, Suwanee, GA, USA) and were mounted using cover slips.

Statistical analysis. To determine whether the interaction between rapamycin and vismodegib was synergistic, additive, or antagonistic, we used the combination index (CI) method of Chou and Talalay (Chou and Talalay, 1984). Combination index $=1$ indicates an additive effect, $\mathrm{CI}<1$ a synergistic effect, and $\mathrm{CI}>1$ an antagonistic effect. Results are expressed as the mean \pm s.d. of the indicated number of independent experiments. Student's $t$-test was calculated to compare the mean of each group with that of the control group. $P$ values of $<0.05$ were considered significant. The statistical analysis of data in this study was performed using Student's $t$-test.

\section{RESULTS}

Hedgehog and mTOR pathway gene and protein expression in BTC cell lines. We first examined the mutation profile of nine known BTC cell lines for commonly mutated human oncogenes. We used a mass spectroscopy-based profiling for 159 point ('hot spot') mutations in 33 genes commonly involved in solid tumours. Our results indicated there were no significant hotspot mutations in these cell lines (Supplementary Information 2). We then conducted quantitative real-time RT-PCR assays to examine the relative expression levels of p70S6K and Gli1 in all 9 BTC cell lines, as indicated by the fold change relative to the gene with the lowest expression level (Figure 1). The real-time RT-PCR results showed a relatively high p70S6K and low Glil gene expression in Mz-ChA-1 cells and relatively low p70S6K and high Gli1 gene expression in Sk-ChA-1 cells. On western blotting, downregulation of p-p70S6K and p-Glil with vismodegib and rapamycin was noted in Mz-ChA1 and Sk-ChA-1 cell lines (Supplementary Information 3). Therefore, we chose these two cell lines for further study. Prior phase I studies with the $\mathrm{Hh}$ antagonist, vismodegib, have successfully examined Glil expression using RT-PCR to measure the pharmacodynamic modulation of the $\mathrm{Hh}$ pathway in the
A

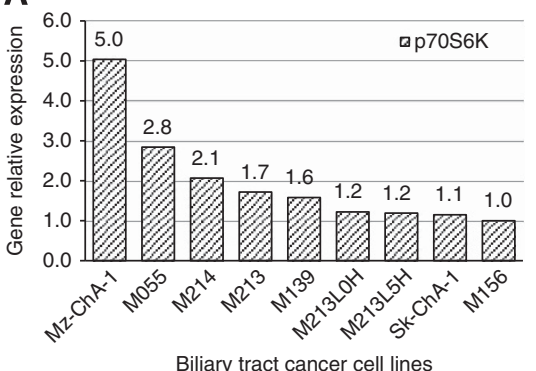

$\mathbf{B}$

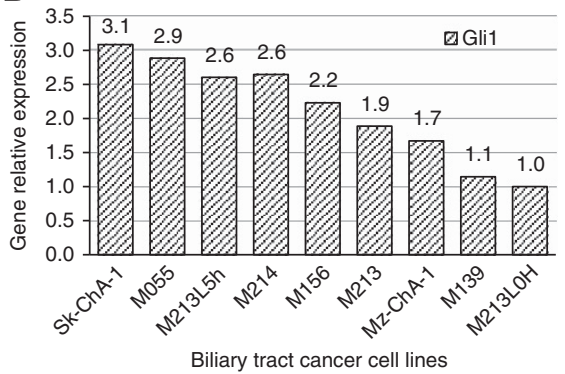

Figure 1. Relative expression levels of p70S6K and Gli1 in BTC cell lines. Real-time RT-PCR analysis of p70S6k and Gli1 relative expression in BTC cell lines. Values represent differences in normalised expression levels compared with the lowest gene expression (normalised against GAPDH mRNA levels). (A) p70S6K expression differences in BTC cell lines compared with M156 cell line. (B) Gli1 expression differences in BTC cell lines compared with M213LOH cell line. 
clinical setting (Von Hoff et al, 2009; Wong et al, 2011). As noted earlier, the crosstalk between the mTOR/S6K1 and Hh signalling pathway is through S6K1-mediated regulation of Gli1 in oesophageal cancer, thus p70 S6K1 was chosen for measurement of mTOR activity (Wang et al, 2012). We therefore used p70S6K and Glil as the surrogate biomarkers of mTOR and Hh pathway activation, respectively.

Effects of rapamycin, vismodegib, and both on BTC cell viability and proliferation. To explore the effects of rapamycin, vismodegib, and both on BTC cell proliferation, we used the CellTiterGlo (Promega) luminescent cell viability assay to examine whether the combined treatment enhanced the inhibition of cell proliferation affected by either agent alone. Mz-ChA-1 and SkChA-1 cells were treated at serial concentrations for $72 \mathrm{~h}$. Our results showed that rapamycin and vismodegib inhibited proliferation in both cell lines in a concentration-dependent manner and that $\mathrm{Mz}-\mathrm{ChA}-1$ cells were more sensitive than SkChA-1 cells to both drugs (Figure $2 \mathrm{~A}$ and $\mathrm{B}$ ). The results also suggested that combination therapy reduced cell viability more than either agent alone did.

To determine whether the combined treatment had a synergistic effect on cell viability, the CI values were calculated according to the method of Chou and Talalay (Table 1). The combination of vismodegib and rapamycin resulted in synergistic interaction in $\mathrm{Mz}$-ChA-1 cells at $\mathrm{IC}_{50}, \mathrm{IC}_{75}$, and $\mathrm{IC}_{90}$, and the $\mathrm{CI}$ values were
$0.40 \pm 0.12,0.39 \pm 0.16$, and $0.40 \pm 0.16$, respectively. A modest additive effect also was observed for Sk-ChA-1 cells at $\mathrm{IC}_{50}, \mathrm{IC}_{75}$ and $\mathrm{IC}_{90}$, and the $\mathrm{CI}$ values were $0.96 \pm 0.18,1.08 \pm 0.25$, and $0.78 \pm 0.17$, respectively. In the colony-formation assays, compared with the control or vismodegib, rapamycin individually, the combination treatment significantly inhibited $\mathrm{Mz}-\mathrm{ChA}-1$ cell colony formation $(P<0.01)$. For Sk-ChA-1 cell, the combination treatment also inhibited the colony formation $(P<0.05)$ (Figure $2 \mathrm{C}$ and $\mathrm{D}$ ).

To evaluate whether vismodegib, rapamycin, or their combination can inhibit cell proliferation via regulation of cell-cycle arrest, cell-cycle analysis was carried out by flow cytometry (Figure 3 ). Cells were treated with rapamycin, vismodegib, or both for $48 \mathrm{~h}$. Vismodegib alone increased the accumulation of Sk-ChA-1cells in the $\mathrm{S}$ phase but had no notable effect on Mz-ChA-1 cells. Rapamycin alone arrested Mz-ChA-1 cells in the G1 phase and decreased the cell population in the $S$ phase but had no notable effect on the Sk-ChA-1 cell population. For both cell lines, the combination of vismodegib and rapamycin arrested cells in the G1 phase and decreased the $S$ phase cell population, although vismodegib alone increased the transition from G1 to $S$ phase in the SK-ChA-1 cell population.

Effects of vismodegib, rapamycin, or both on BTC stem cell populations. Cancer stem cells have the exclusive ability to regenerate tumors. The capacity to generate a tumour sphere in nonadherent culture condition is a CSC characteristic. Mz-ChA-1

Table 1. Synergistic effect of combination treatment with rapamycin and vismodegib on BTC cells

\begin{tabular}{|c|c|c|c|c|c|}
\hline \multicolumn{6}{|c|}{$I C_{50} \pm$ s.d. } \\
\hline & & & \multicolumn{2}{|c|}{ Combination treatment } & \\
\hline Cell line & Rapamycin ( $\mu \mathrm{M})$ & Vismodegib $(\mu \mathrm{M})$ & Rapamycin $(\mu \mathrm{M})$ & Vismodegib ( $\mu \mathrm{M})$ & Combination index \\
\hline Mz-ChA-1 & $3.31 \pm 0.26$ & $54.97 \pm 3.45$ & $0.82 \pm 0.18$ & $8.19 \pm 1.02$ & $0.40 \pm 0.12$ \\
\hline Sk-ChA-1 & $3.53 \pm 0.31$ & $74.54 \pm 2.58$ & $2.28 \pm 0.21$ & $22.83 \pm 1.35$ & $0.96 \pm 0.18$ \\
\hline
\end{tabular}

A

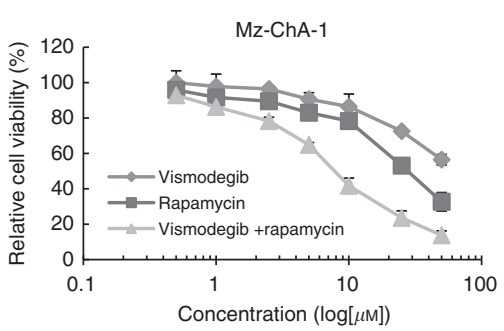

C

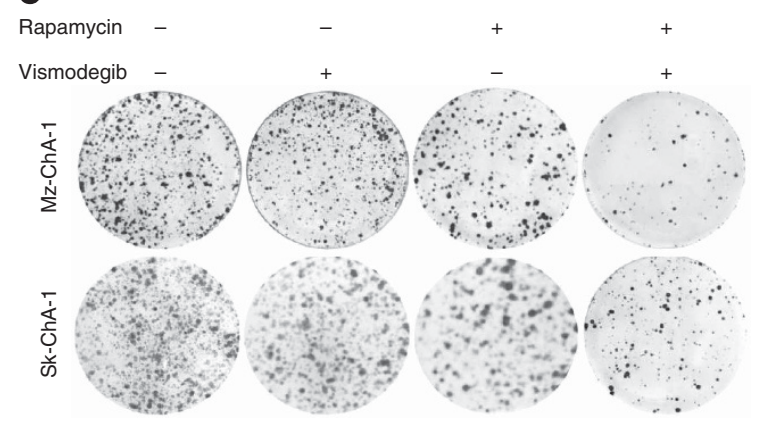

B

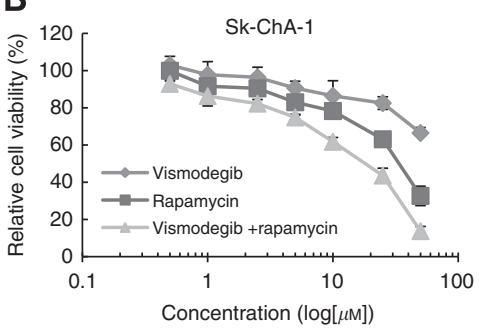

D

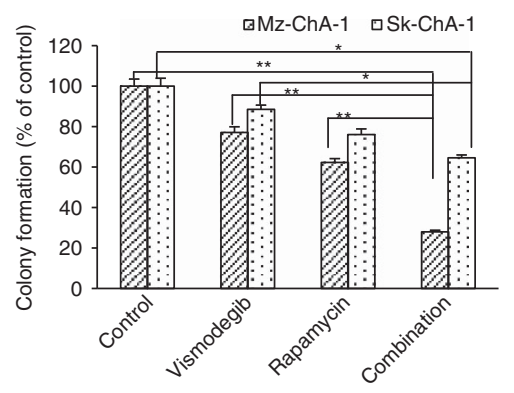

Figure 2. Effect of rapamycin, vismodegib, and both on BTC cell survival and proliferation. (A) Mz-ChA-1 and (B) Sk-ChA-1 cells were treated for $72 \mathrm{~h}$ at serial concentrations $\left(0.25-50 \mu \mathrm{mol} \mathrm{I}^{-1}\right)$. Rapamycin, vismodegib, and both caused a dose-dependent decrease in BTC cell proliferation, as measured by the CellTiter-Glo assay. (C) Clonogenic assay. Cells were treated with DMSO (control), $1 \mu$ moll $I^{-1}$ rapamycin, $10 \mu$ moll $I^{-1}$ vismodegib, or both for $72 \mathrm{~h}$, cells stained with $0.5 \%$ crystal violet. (D) Colony numbers as determined by clonogenic assay. The number of colonies with $\geqslant 50$ cells was counted. Values are mean \pm s.d. Results are representative of three independent experiments. ${ }^{\star} P<0.05,{ }^{\star \star} P<0.01$. 
cells and Sk-ChA-1 cells were cultured in 24-well ultralowattachment plates and treated with vehicle (DMSO; control), $1 \mu \mathrm{moll}^{-1}$ rapamycin, $10 \mu \mathrm{moll}^{-1}$ vismodegib, or both rapamycin and vismodegib for 7 days. The combination of the two drugs dramatically reduced the total number and size of the tumour spheres compared with the control group, especially for Mz-ChA-1 cells (Figure 4A and B).

In order to further evaluate the effects of vismodegib, rapamycin, and both agents on CSCs, we used real-time RT-PCR to examine CSC-related gene expression in the tumour spheres.
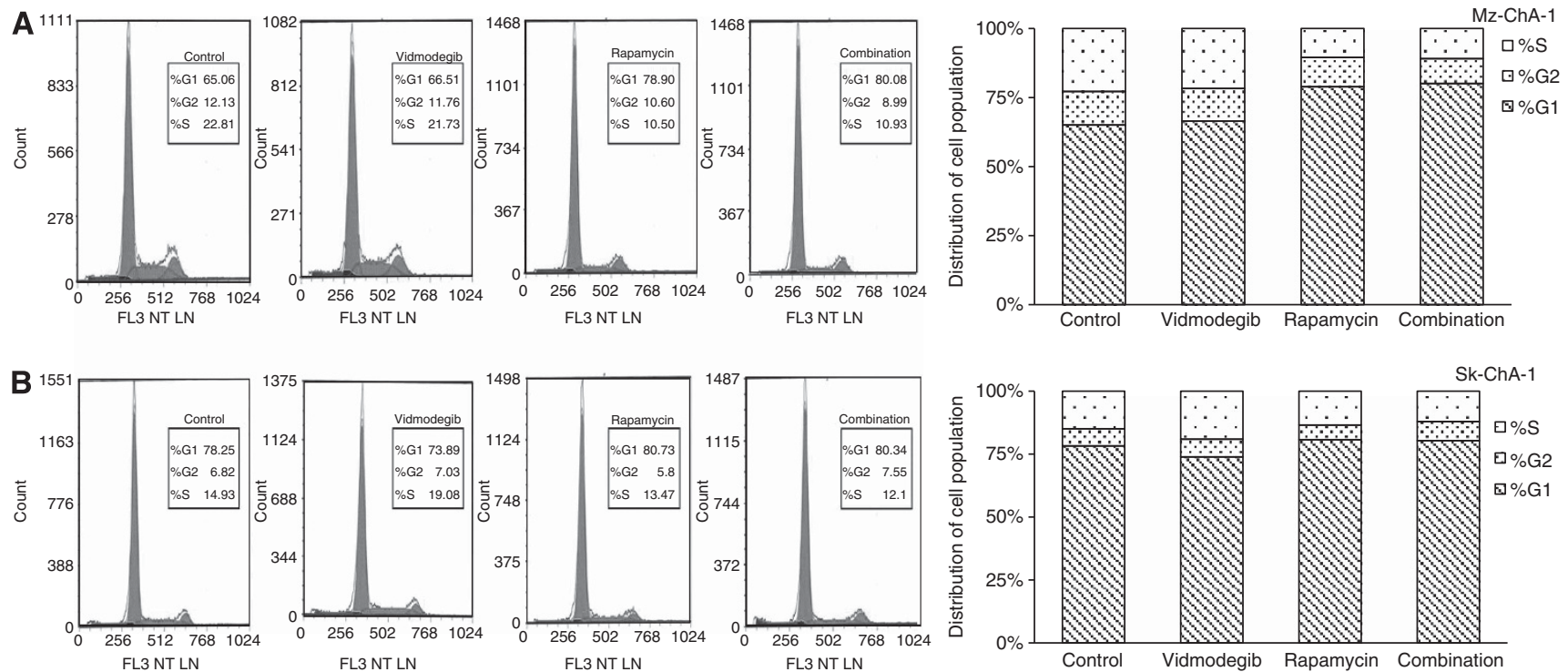

Figure 3. Cell-cycle analysis. (A) Mz-ChA-1 and (B) Sk-ChA-1 cells were treated with $1 \mu$ moll ${ }^{-1}$ rapamycin, $10 \mu$ mol I-1 vismodegib, or both for $72 \mathrm{~h}$. Cell-cycle distribution was analyzed by flow cytometry.

A

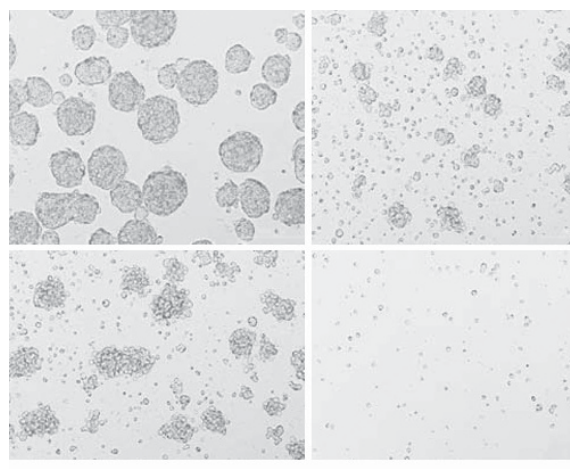

B

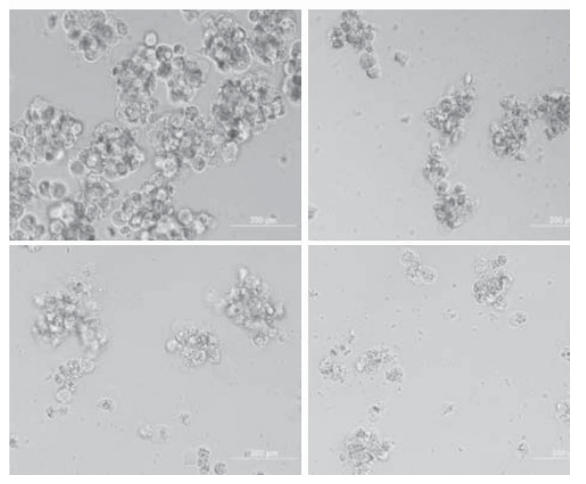

C

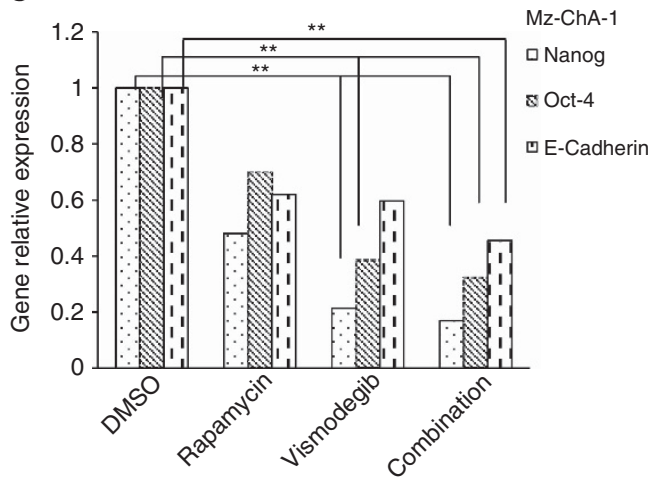

D

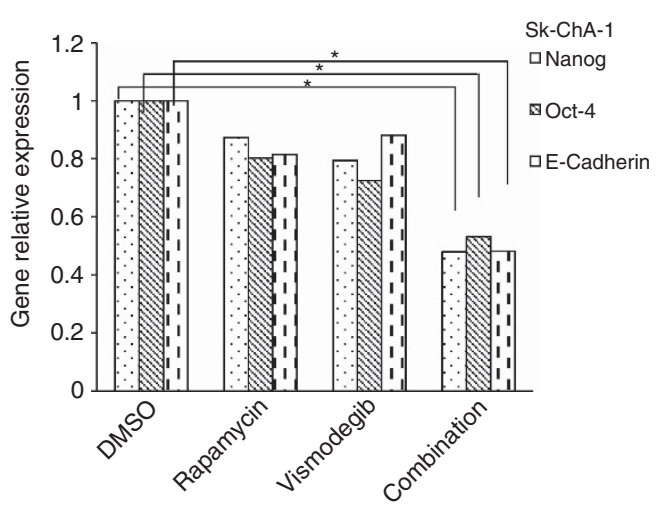

Figure 4. Effect of rapamycin, vismodegib, or both on stem cell sphere formation. Effects of vismodegib, rapamycin or both on tumoursphere formation and Nanog, Oct-4, and E-Cadherin gene expression. Mz-ChA-1 (A) and Sk-ChA-1 (B) tumour spheres. Third passage single cells were cultured for $72 \mathrm{~h}$, and then treated with vehicle, rapamycin $\left(1 \mu \mathrm{moll} \mathrm{I}^{-1}\right)$, vismodegib $\left(10 \mu \mathrm{moll} \mathrm{I}^{-1}\right)$, or both for 7 days. Tumourspheres were imaged by Olympus microscope. Compared with control group, the combination treatment inhibited Nanog, Oct-4, and E-Cadherin expression in Mz-ChA-1 (C) (**P<0.01) and Sk-ChA-1 (D) ( $\left.{ }^{\star} P<0.05\right)$. 
The results showed that combined treatment significantly decreased the Nanog, Oct-4, and E-cadherin gene expression in both Mz-ChA-1 and Sk-ChA-1 CSCs compared with the DMSO (control) group (Figure 4C and D).

Aldehyde dehydrogenase was also investigated as a possible marker for identifying CSCs, including BTC stem cells. We performed the ALDEFLUOR assay to explore the effect of the treatment agents on the Mz-ChA-1 and Sk-ChA-1 CSC populations (Figure 5A and D). The combined treatment significantly reduced the ALDH-positive population in $\mathrm{Mz}-\mathrm{ChA}-1$ cells but not in Sk-ChA-1 cells (Figure 5C and D).

Effects of vismodegib, rapamycin, and both on mTOR and Hh pathway signalling. We investigated the activity of rapamycin, vismodegib, and both on mTOR and Hh signalling in BTC cells by using western blots. The Mz-ChA-1 and Sk-ChA-1 cells were treated with rapamycin, vismodegib, or both for $48 \mathrm{~h}$. We examined the expression levels of p70S6K, p-p70S6K, AKT, p-AKT $\left(\operatorname{Ser}^{473}\right)$, Gli1, p-Gli1, mTOR, and p-mTOR. The initial ratios of $\mathrm{pS} 6 \mathrm{~K} / \mathrm{S} 6$ in $\mathrm{Mz}-\mathrm{ChA}-1$ and Sk-ChA-1 cells were $51.62 \pm 9.07 \%$ and $13.22 \pm 2.03 \%$, respectively. The results showed that, for both cell lines, the expression of the phosphorylated proteins was significantly decreased in the combined treatment group (Figure 6). The western blotting results were repeated three times and with reproducible results.

Anti-tumour activity of the combination of rapamycin and vismodegib in a xenograft model. We next evaluated the antitumour activity of vismodegib, rapamycin, or both in vivo with a xenograft mouse model. Single-cell suspensions of $5 \times 10^{6} \mathrm{Mz}$ ChA-1 cells were subcutaneously injected into the right flank of 32 athymic nude mice. Once tumours grew to approximately $100 \mathrm{~mm}^{3}$, the mice were randomly allocated into four treatment arms (vehicle only, rapamycin, vismodegib, or both rapamycin and vismodegib) and treated twice daily through oral gavage.
Compared with the control group, at day 27, tumour xenograft growth was $39.42 \pm 12.33 \%, 51.03 \pm 5.71 \%$, and $80.39 \pm 11.18 \%$ $(P<0.01)$ lower in the rapamycin, vismodegib, and combination groups, respectively (Figure $7 \mathrm{~A}$ ). The xenograft tumour doubling time was $7.11 \pm 0.88,9.31 \pm 1.29,12.40 \pm 2.01$, and $20.04 \pm 5.48$ days in the control, rapamycin, vismodegib, and combined treatment groups. Nude mice were killed on day 27 because of the tumour size.

The mice tolerated the treatments without overt signs of toxicity. Body weight did not differ significantly between treatment groups (Figure 7B), and no adverse effects such as hunched posture, ruffled fur, and hypothermia were observed. Immunohistochemical assay results for the xenograft tumour tissues showed that the combined treatment significantly decreased p-p70S6K and Gli1 protein expression levels as compared with the control (vehicle only) group in vivo (Figure 7C).

Immunohistochemical analysis of human samples of gallbladder cancer. In order to identify potential predictive biomarkers for vismodegib and mTOR inhibitors in human specimens, we investigated the protein expression levels of Gli1 and p-p70S6K in cases of resected gallbladder cancer. Our immunohistochemical results revealed a relatively high p-p70S6K protein level and low Gli1 protein expression level in 4 of 10 cases examined (Figure 8). This immunohistochemical pattern was similar to those we found in $\mathrm{Mz}$-ChA-1 cell lines.

\section{DISCUSSION}

The combination of rapamycin and vismodegib significantly inhibited BTC cell viability and proliferation in our study; this effect was confirmed with our in vivo study. The protein expression levels of p-p70S6K, p-mTOR, p-Gli1, and p-AKT in Mz-ChA-1 and Sk-ChA-1 cells were decreased by the combination regimen.
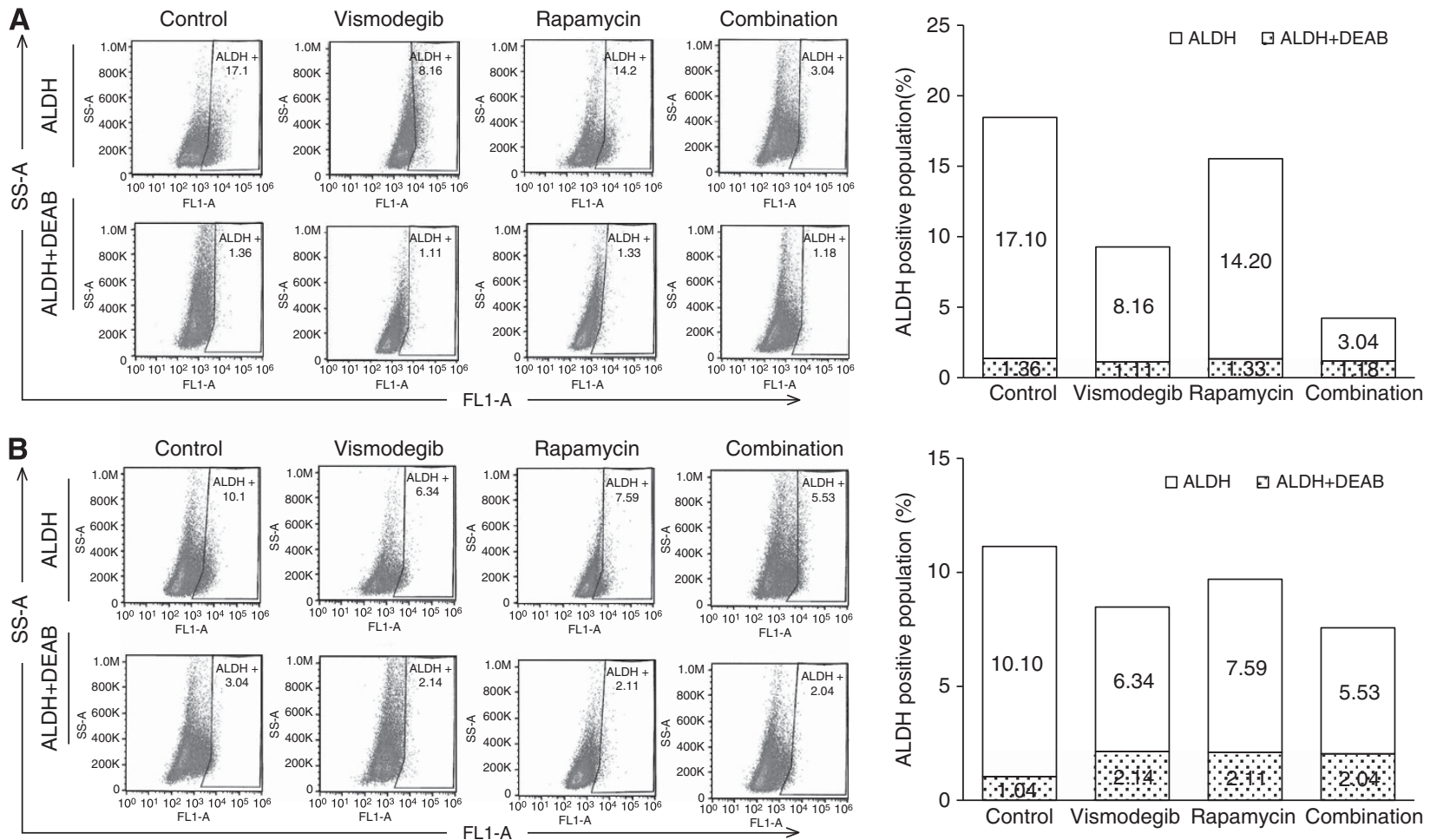

Figure 5. ALDH activity measured by FACS analysis. Aldefluor analysis of Mz-ChA-1 cells (A) and Sk-ChA-1 cells (B) treated with vehicle, rapamycin $\left(1 \mu \mathrm{moll} \mathrm{I}^{-1}\right)$, vismodegib $\left(10 \mu \mathrm{mol} \mathrm{I}^{-1}\right)$, or both for $72 \mathrm{~h}$. ALDH ${ }^{+} \mathrm{Mz}-\mathrm{ChA}-1$ cells were significantly decreased in the combined treatment group (compared with control and vismodegib, $P<0.01$ and $P<0.05$, respectively). 

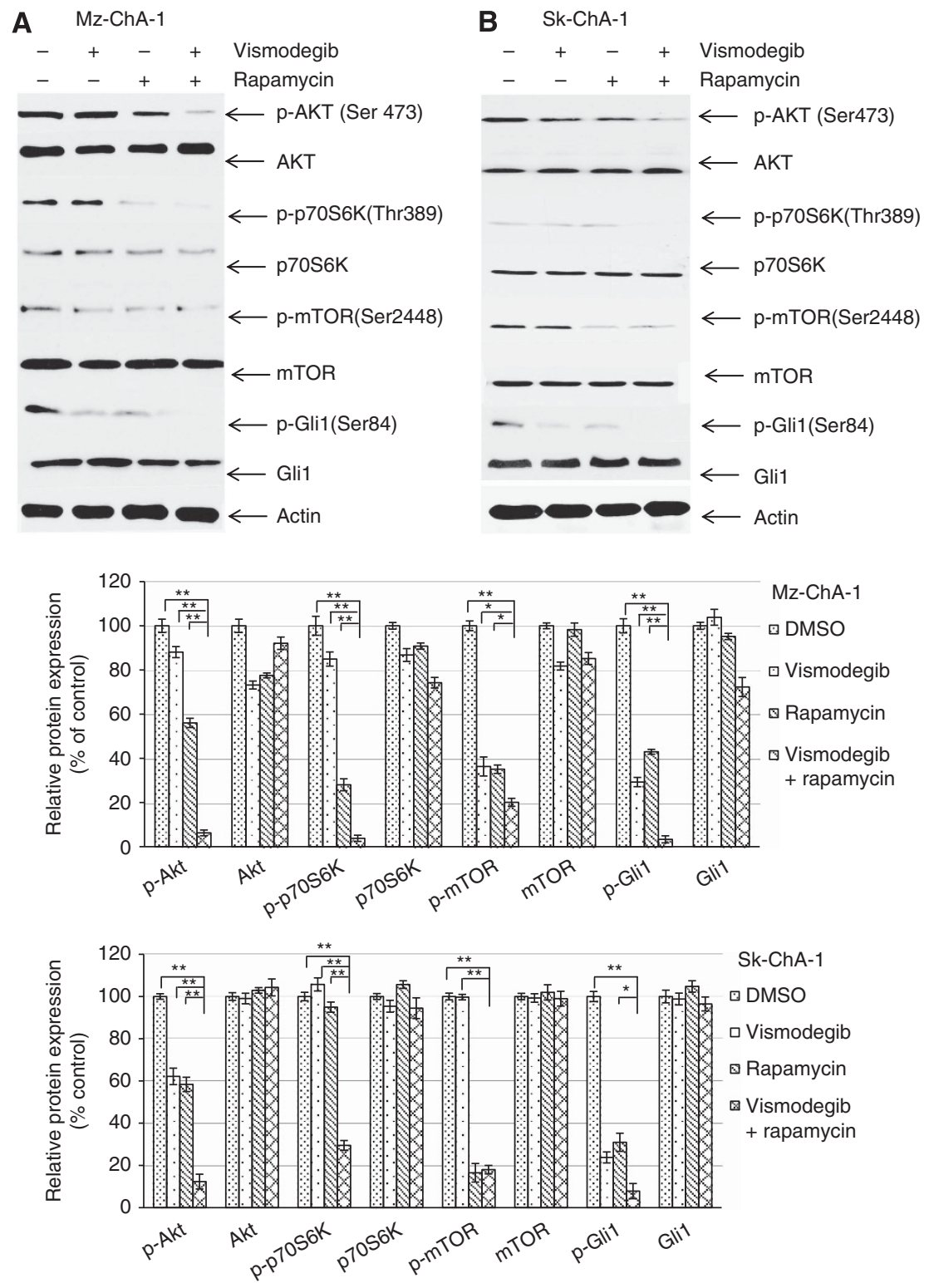

Figure 6. Effect of rapamycin, vismodegib, or both on protein expression. Mz-ChA-1 cells (A) and Sk-ChA-1 cells (B) were treated with vehicle, rapamycin $\left(1 \mu \mathrm{moll} \mathrm{I}^{-1}\right)$, vismodegib $\left(10 \mu \mathrm{moll} \mathrm{I}^{-1}\right)$, or both for $24 \mathrm{~h}$. Actin was used as a loading control $\left({ }^{\star} P<0.05,{ }^{\star \star} P<0.01\right)$.

Decreased expression of p-p70S6K and Glil was noted in the BTC xenografts treated with this combination. High p-p70S6K expression along with low Gli1 expression was observed in Mz-ChA-1 cell lines, which were sensitive to the combination regimen. This expression pattern was also noted in $40 \%$ of the human BTC cases we examined.

Biliary tract cancer represents a diverse and genetically heterogeneous group of cancers, which makes the implementation of molecular therapy challenging. CCA and gallbladder cancer are often grouped together as BTCs in clinical trials despite their divergent clinical presentation and genetic background. Furthermore, there are very few BTC cell lines and preclinical in vivo models. All of these factors make the development of novel therapies in BTC challenging. Recently, there have been promising genomic and transcriptional profiling studies in intrahepatic CCA that suggest that this disease has distinct molecular subsets, some of which may be amenable to targeted therapy (Andersen et al, 2012; Borger et al, 2012; Sia et al, 2013; Voss et al, 2013).

The activation of Hh signalling is common in BTC and has prognostic implications. Tang et al (2013) recently demonstrated that Glil expression was associated with a poor prognosis in CCA and demonstrated that inhibition of Hh signalling with cyclopamine led to apoptosis in CCA cells (Tang et al, 2013). Canonical activation of $\mathrm{Hh}$ signalling involves $\mathrm{Hh}$ ligand binding to its receptor, $\mathrm{PTCH}$, which results in the activation of Smo and is followed by activation of Gli transcription factors. A critical role of Smo-independent regulation of Gli activity by several other signalling pathways, including the PI3K/AKT and RAS/RAF/ MEK/ERK pathways, has been suggested (Lauth and Toftgard, 2007; Jenkins, 2009). Canonical Hh signalling is attenuated in CCA, and non-canonical Hh signalling contributes to disease progression, thereby supporting a role for $\mathrm{Hh}$ and other targeted inhibitors in this disease (Razumilava et al, 2014). In our study, combined mTOR- and Hh-directed therapy had the optimal antitumour effect in BTC cell lines, particularly Mz-ChA-1. Although combined therapy was superior, inhibition of p70S6K also occurred with vismodegib and p-Gli1 with rapamycin, which supports the idea of bi-directional cross talk between the pathways. Our group described the proposed mechanism of this cross talk in a previous report: activated mTOR pathway promotes Gli1 

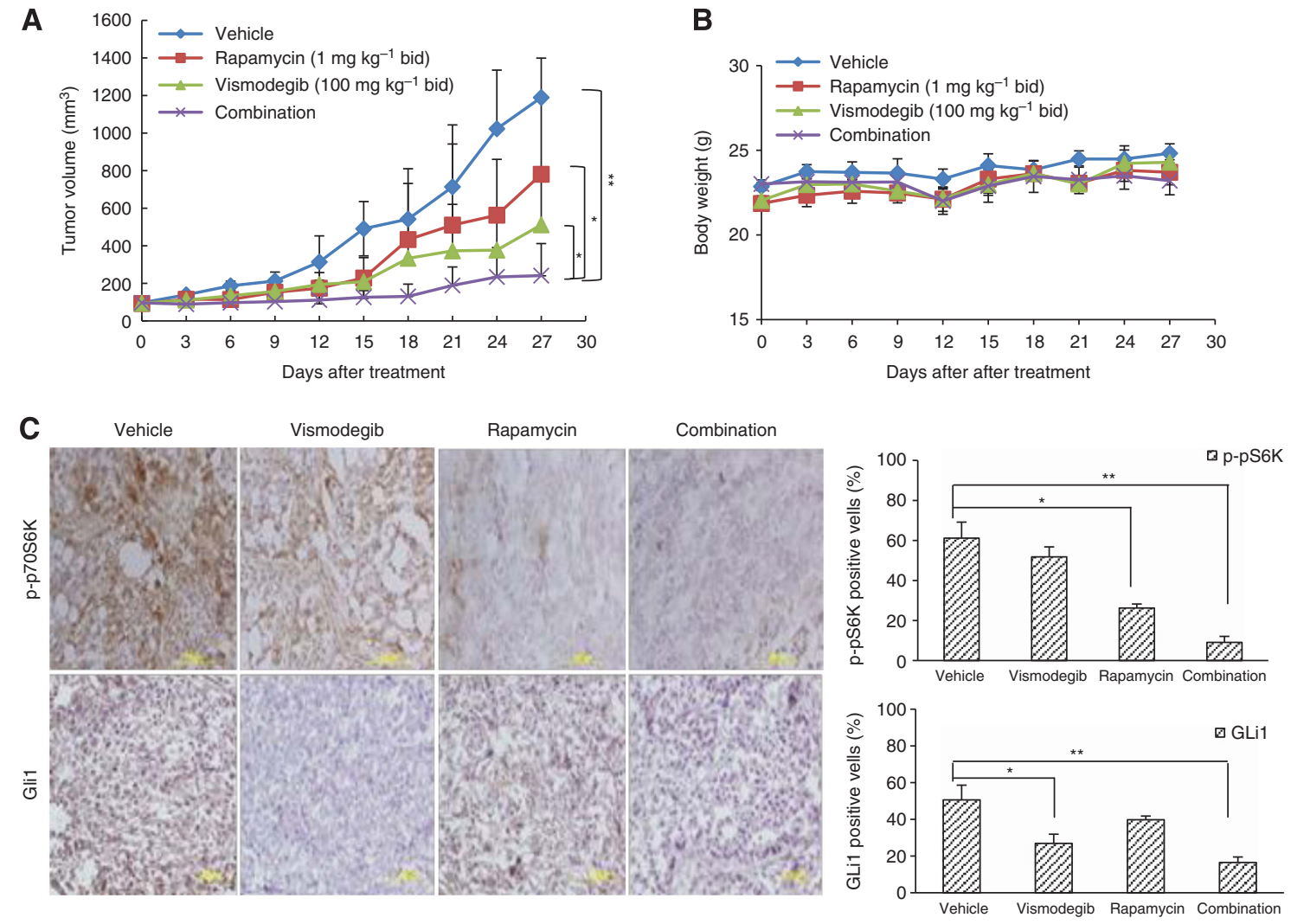

Figure 7. Effect of rapamycin, vismodegib, or both on Mz-ChA-1 cell xenograft tumors. (A) Effects on xenograft growth. Mice treated with vehicle only, rapamycin $\left(1 \mathrm{mg} \mathrm{kg}^{-1}\right.$, b.i.d.), vismodegib $\left(100 \mathrm{mg} \mathrm{kg}^{-1}\right.$, b.i.d.), or both when tumour volume reached $100 \mathrm{~mm}^{3}$. Values are expressed as mean \pm s.d. ( $n=8$ mice per treatment group). (B) Nude mouse weight. The mice were weighed every 3 days and there was no significant change in nude mice weight. Values are expressed as mean \pm s.d. (C) Immunohistochemical analysis of xenograft tumour tissue. Tumour tissues were subjected to immunostaining for p-p70S6K and Gli1 protein expression. Quantified p-p70S6K and Gli1 protein expression levels in a representative xenograft tumour from each treatment group are shown at right. ${ }^{\star} P<0.05,{ }^{\star \star} P<0.01$.

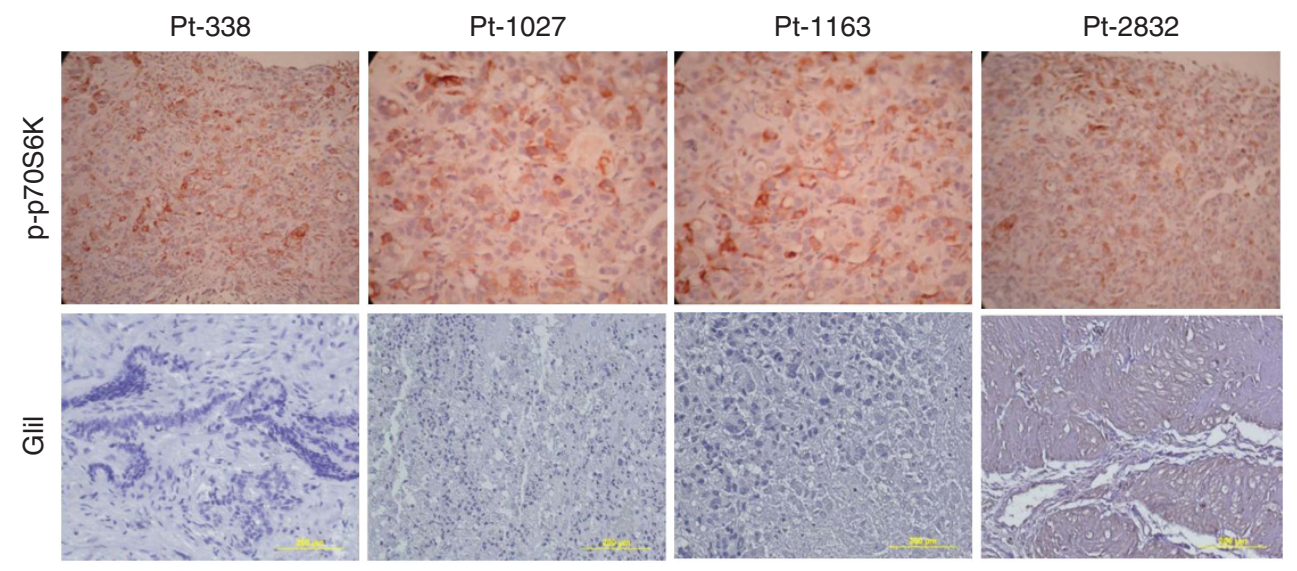

Figure 8. Immunohistochemical analysis of p-p70S6K and Gli1 protein expression. Ten gallbladder cancer patient tumours were examined and four patient tumours with high p-p70 S6K and low Gli1 protein expression.

transcriptional activity and oncogenic function through p70S6K1mediated Gli1 phosphorylation at Ser ${ }^{84}$, which releases Gli1 from its endogenous inhibitor, SuFu (Wang et al, 2012).

For studies of the combined inhibition of $\mathrm{Hh}$ signalling and mTOR in BTC cells, it would be useful to identify a potential clinical phenotype for investigational therapy. For our study, we first characterised the BTC cell lines for p70S6K and Gli1 gene expression. We chose the Mz-ChA-1 and Sk-ChA-1 cell lines for further investigation, as these represented relative extremes of
p70S6K and Gli1 gene expression levels, with Mz-ChA-1 cells having a high $p 70 S 6 \mathrm{~K}$ gene expression level and Sk-ChA-1 having a high Gli1 gene expression level. Furthermore, these cell lines have been widely used in prior BTC preclinical studies. The cell line MzChA-1, which is derived from gallbladder cancer, was significantly inhibited by the combination of vismodegib and rapamycin. The dose of rapamycin and vismodegib used in vivo, when converted to human equivalent doses are within clinically acceptable dose ranges (Supplementary Information 4) (LoRusso et al, 2011; 
Acevedo-Gadea et al, 2014). Our results also showed that the combination of vismodegib and rapamycin significantly inhibited stem cell tumour sphere formation and downregulated Nanog, Oct-4, and E-cadherin gene expression level. Nanog and Oct-4 are essential for maintaining the pluripotency of embryonic stem cells, whereas aberrant expression of E-cadherin has been associated with the development of metastases. Although the prevailing belief is that loss of E-cadherin is a prerequisite for progression to metastatic disease and tumourigenesis, tumours are actually remarkably heterogeneous and E-cadherin loss does not always correlate with invasion. E-cadherin is also highly overexpressed in prostate cancer, inflammatory breast cancer, and early-stage ovarian carcinoma. E-cadherin enhances proliferation and survival by inducing ligand-independent activation of the receptor tyrosine kinase epidermal growth factor receptor (Putzke et al, 2011; David and Rajasekaran, 2012). Loss of E-cadherin regulation and expression levels in stem cells is likely to reflect the different culture conditions for these cell lines (Mohamet et al, 2011). High ALDH activity is a characteristic of CSCs in several malignancies, including BTC (Douville et al, 2009). In our study, ALDH activity was notably decreased in Mz-ChA-1 cells with the combined treatment but not in Sk-ChA-1 cells, which supports a role for combination therapy against CSCs in a subset of BTCs.

In summary, the addition of vismodegib to an mTOR inhibitor may lead to an incremental anti-tumour effect in BTCs. In particular, a high $\mathrm{p} 70 \mathrm{~S} 6 \mathrm{~K} / \mathrm{Gli}$ gene expression ratio may predict responsiveness to the combination in the clinical setting.

\section{ACKNOWLEDGEMENTS}

We thank the Cholangiocarcinoma Foundation for their support. We thank Dr Shrikanth A. Reddy and Dr Yong Sun Lee for kindly providing the BTC cell lines.

\section{CONFLICT OF INTEREST}

The authors declare no conflict of interest.

\section{REFERENCES}

Acevedo-Gadea C, Santin AD, Higgins SA, Urva S, Ratner E, Silasi DA, Azodi M, Rutherford T, Schwartz PE, Abu-Khalaf MM (2014) Phase I clinical trial of the mammalian target of rapamycin inhibitor everolimus in combination with oral topotecan for recurrent and advanced endometrial cancer. Int J Gynecol Cancer 24(3): 528-533.

Andersen JB, Spee B, Blechacz BR, Avital I, Komuta M, Barbour A, Conner EA, Gillen MC, Roskams T, Roberts LR, Factor VM, Thorgeirsson SS (2012) Genomic and genetic characterization of cholangiocarcinoma identifies therapeutic targets for tyrosine kinase inhibitors. Gastroenterology 142(4): 1021-1031 e1015.

Borger DR, Tanabe KK, Fan KC, Lopez HU, Fantin VR, Straley KS, Schenkein DP, Hezel AF, Ancukiewicz M, Liebman HM, Kwak EL, Clark JW, Ryan DP, Deshpande V, Dias-Santagata D, Ellisen LW, Zhu AX, Iafrate AJ (2012) Frequent mutation of isocitrate dehydrogenase (IDH) 1 and IDH2 in cholangiocarcinoma identified through broad-based tumor genotyping. Oncologist 17(1): 72-79.

Buzzoni R, Pusceddu S, Bajetta E, De Braud F, Platania M, Iannacone C, Cantore M, Mambrini A, Bertolini A, Alabiso O, Ciarlo A, Turco C, Mazzaferro V (2014) Activity and safety of RAD001 (everolimus) in patients affected by biliary tract cancer progressing after prior chemotherapy: a phase II ITMO study. Ann Oncol 25(8): 1597-1603.

Chou TC, Talalay P (1984) Quantitative analysis of dose-effect relationships: the combined effects of multiple drugs or enzyme inhibitors. Adv Enzyme Regul 22: 27-55.

David JM, Rajasekaran AK (2012) Dishonorable discharge: the oncogenic roles of cleaved E-cadherin fragments. Cancer Res 72(12): 2917-2923.
Douville J, Beaulieu R, Balicki D (2009) ALDH1 as a functional marker of cancer stem and progenitor cells. Stem Cells Dev 18(1): $17-25$.

El Khatib M, Kalnytska A, Palagani V, Kossatz U, Manns MP, Malek NP, Wilkens L, Plentz RR (2013) Inhibition of hedgehog signaling attenuates carcinogenesis in vitro and increases necrosis of cholangiocellular carcinoma. Hepatology 57(3): 1035-1045.

Herberger B, Berger W, Puhalla H, Schmid K, Novak S, Brandstetter A, Pirker C, Gruenberger T, Filipits M (2009) Simultaneous blockade of the epidermal growth factor receptor/mammalian target of rapamycin pathway by epidermal growth factor receptor inhibitors and rapamycin results in reduced cell growth and survival in biliary tract cancer cells. Mol Cancer Ther 8(6): 1547-1556.

Herberger B, Puhalla H, Lehnert M, Wrba F, Novak S, Brandstetter A, Gruenberger B, Gruenberger T, Pirker R, Filipits M (2007) Activated mammalian target of rapamycin is an adverse prognostic factor in patients with biliary tract adenocarcinoma. Clin Cancer Res 13(16): 4795-4799.

Jenkins D (2009) Hedgehog signalling: emerging evidence for non-canonical pathways. Cel Signal 21(7): 1023-1034.

Kim YJ, Park SB, Park JY, Park SW, Chung JB, Song SY, Bang S (2012) The sonic hedgehog pathway as a treatment target for extrahepatic biliary tract cancer. Mol Med Rep 5(1): 12-16.

Lauth M, Toftgard R (2007) Non-canonical activation of GLI transcription factors: implications for targeted anti-cancer therapy. Cell Cycle 6(20): 2458-2463.

Leal P, Garcia P, Sandoval A, Letelier P, Brebi P, Ili C, Alvarez H, Tapia O, Roa JC (2013) Immunohistochemical expression of phospho-mTOR is associated with poor prognosis in patients with gallbladder adenocarcinoma. Arch Pathol Lab Med 137(4): 552-557.

LoRusso PM, Rudin CM, Reddy JC, Tibes R, Weiss GJ, Borad MJ, Hann CL, Brahmer JR, Chang I, Darbonne WC, Graham RA, Zerivitz KL, Low JA, Von Hoff DD (2011) Phase I trial of hedgehog pathway inhibitor vismodegib (GDC-0449) in patients with refractory, locally advanced or metastatic solid tumors. Clin Cancer Res 17(8): 2502-2511.

Mohamet L, Hawkins K, Ward CM (2011) Loss of function of e-cadherin in embryonic stem cells and the relevance to models of tumorigenesis. J Oncol 2011: 352616.

Moolthiya P, Tohtong R, Keeratichamroen S, Leelawat K (2014) Role of mTOR inhibitor in cholangiocarcinoma cell progression. Oncol Lett 7(3): 854-860.

Poomphakwaen K, Promthet S, Kamsa-Ard S, Vatanasapt P, Chaveepojnkamjorn W, Klaewkla J, Sujirarat D, Pichainarong N (2009) Risk factors for cholangiocarcinoma in Khon Kaen, Thailand: a nested case-control study. Asian Pac J Cancer Prev 10(2): 251-258.

Putzke AP, Ventura AP, Bailey AM, Akture C, Opoku-Ansah J, Celiktas M, Hwang MS, Darling DS, Coleman IM, Nelson PS, Nguyen HM, Corey E, Tewari M, Morrissey C, Vessella RL, Knudsen BS (2011) Metastatic progression of prostate cancer and e-cadherin regulation by zeb1 and SRC family kinases. Am J Pathol 179(1): 400-410.

Razumilava N, Gradilone SA, Smoot RL, Mertens JC, Bronk SF, Sirica AE, Gores GJ (2014) Non-canonical Hedgehog signaling contributes to chemotaxis in cholangiocarcinoma. J Hepatol 60(3): 599-605.

Riedlinger D, Bahra M, Boas-Knoop S, Lippert S, Bradtmoller M, Guse K, Seehofer D, Bova R, Sauer IM, Neuhaus P, Koch A, Kamphues C (2014) Hedgehog pathway as a potential treatment target in human cholangiocarcinoma. J Hepatobiliary Pancreat Sci 21(8): 607-615.

Rodova M, Fu J, Watkins DN, Srivastava RK, Shankar S (2012) Sonic hedgehog signaling inhibition provides opportunities for targeted therapy by sulforaphane in regulating pancreatic cancer stem cell self-renewal. PLoS One 7(9): e46083.

Sia D, Hoshida Y, Villanueva A, Roayaie S, Ferrer J, Tabak B, Peix J, Sole M, Tovar V, Alsinet C, Cornella H, Klotzle B, Fan JB, Cotsoglou C, Thung SN, Fuster J, Waxman S, Garcia-Valdecasas JC, Bruix J, Schwartz ME, Beroukhim R, Mazzaferro V, Llovet JM (2013) Integrative molecular analysis of intrahepatic cholangiocarcinoma reveals 2 classes that have different outcomes. Gastroenterology 144(4): 829-840.

Siegel R, Ma J, Zou Z, Jemal A (2014) Cancer statistics, 2014. CA Cancer J Clin 64(1): 9-29.

Simbolo M, Fassan M, Ruzzenente A, Mafficini A, Wood LD, Corbo V, Melisi D, Malleo G, Vicentini C, Malpeli G, Antonello D, Sperandio N, Capelli P, Tomezzoli A, Iacono C, Lawlor RT, Bassi C, Hruban RH, Guglielmi A, Tortora G, de Braud F, Scarpa A (2014) Multigene mutational profiling of cholangiocarcinomas identifies actionable molecular subgroups. Oncotarget 5(9): 2839-2852. 
Tang L, Tan YX, Jiang BG, Pan YF, Li SX, Yang GZ, Wang M, Wang Q, Zhang J, Zhou WP, Dong LW, Wang HY (2013) The prognostic significance and therapeutic potential of hedgehog signaling in intrahepatic cholangiocellular carcinoma. Clin Cancer Res 19(8): 2014-2024.

Von Hoff DD, LoRusso PM, Rudin CM, Reddy JC, Yauch RL, Tibes R, Weiss GJ, Borad MJ, Hann CL, Brahmer JR, Mackey HM, Lum BL, Darbonne WC, Marsters Jr. JC, de Sauvage FJ, Low JA (2009) Inhibition of the hedgehog pathway in advanced basal-cell carcinoma. N Engl J Med 361(12): 1164-1172.

Voss JS, Holtegaard LM, Kerr SE, Fritcher EG, Roberts LR, Gores GJ, Zhang J, Highsmith WE, Halling KC, Kipp BR (2013) Molecular profiling of cholangiocarcinoma shows potential for targeted therapy treatment decisions. Hum Pathol 44(7): 1216-1222.

Wang Y, Ding Q, Yen CJ, Xia W, Izzo JG, Lang JY, Li CW, Hsu JL, Miller SA, Wang X, Lee DF, Hsu JM, Huo L, Labaff AM, Liu D, Huang TH, Lai CC, Tsai FJ, Chang WC, Chen CH, Wu TT, Buttar NS, Wang KK, Wu Y, Wang H, Ajani J, Hung MC (2012) The crosstalk of mTOR/S6K1 and Hedgehog pathways. Cancer Cell 21(3): 374-387.
Wong H, Alicke B, West KA, Pacheco P, La H, Januario T, Yauch RL, de Sauvage FJ, Gould SE (2011) Pharmacokinetic-pharmacodynamic analysis of vismodegib in preclinical models of mutational and liganddependent Hedgehog pathway activation. Clin Cancer Res 17(14): 4682-4692.

Wu Q, Kiguchi K, Kawamoto T, Ajiki T, Traag J, Carbajal S, Ruffino L, Thames H, Wistuba I, Thomas M, Vasquez KM, DiGiovanni J (2007) Therapeutic effect of rapamycin on gallbladder cancer in a transgenic mouse model. Cancer Res 67(8): 3794-3800.

Zong H, Yin B, Zhou H, Cai D, Ma B, Xiang Y (2014) Inhibition of mTOR pathway attenuates migration and invasion of gallbladder cancer via EMT inhibition. Mol Biol Rep 41(7): 4507-4512.

This work is published under the standard license to publish agreement. After 12 months the work will become freely available and the license terms will switch to a Creative Commons AttributionNonCommercial-Share Alike 4.0 Unported License.

Supplementary Information accompanies this paper on British Journal of Cancer website (http://www.nature.com/bjc) 